\title{
Female Sexual Function in Women with Suspected Deep Infiltrating Endometriosis
}

\section{Função sexual feminina em mulheres com suspeita de endometriose infiltrativa profunda}

\author{
Ryane Vieira Lima ${ }^{1}$ Ana Maria Gomes Pereira ${ }^{1}$ Fernando Bray Beraldo ${ }^{1}$ Cláudia Gazzo ${ }^{1}$ \\ João Alfredo Martins ${ }^{1}$ Reginaldo Guedes Coelho Lopes ${ }^{1}$ \\ ${ }^{1}$ Hospital do Servidor Público Estadual, São Paulo, SP, Brazil \\ Address for correspondence Ryane Vieira Lima, Medical Resident, \\ Rev Bras Ginecol Obstet 2018;40:115-120. \\ Avenida Ibirapuera, 981, 04038- 034, São Paulo, SP, Brazil \\ (e-mail: ryanevlm@gmail.com).
}

\section{Abstract \\ Keywords \\ - endometriosis \\ - sexuality \\ - deeply infiltrating endometriosis}

Resumo
Objective To evaluate the quality of the sexual function of women with suspected deep infiltrating endometriosis.

Methods A cross-sectional, observational and prospective study was conducted between May 2015 and August 2016, in which 67 patients with deep infiltrating endometriosis, suspected or diagnosed, were assessed for epidemiological and clinical characteristics, such as pain level through a visual analog scale (VAS), features of deep infiltrating endometriosis lesions and score on the Female Sexual Function Index (FSFI) before the onset of treatment. The statistical analysis was performed using the software STATA version 12.0 (StataCorp LLC, College Station, TX, USA) to compare the variables through multiple regression analysis.

Results The average age of the patients was 39.2 years old; most patients were symptomatic (92.5\%); and the predominant location of the deep infiltrating lesions was on the rectosigmoid colon (50\%), closely followed by the retrocervical region (48.3\%). The median overall score on the FSFI was 23.4 ; in $67.2 \%$ of the cases the score was $\leq 26.5$ (cutoff point for sexual dysfunction). Deep dyspareunia ( $p=0.000$, confidence interval [CI]: 0.64$0.83)$ and rectosigmoid endometriosis lesions ( $p=0.008, \mathrm{Cl}: 0.72-0.95)$ showed significant correlation with lower FSFI scores, adjusted by bladder lesion, patients' age and size of lesions. Deep dyspareunia ( $p=0.003, \mathrm{Cl}: 0.49-0.86)$ also exhibited significant correlation with FSFI pain domain, adjusted by cyclic bowel pain, vaginal lesion and use of gonadotropin-releasing hormone $(\mathrm{GnRH})$ analog. These results reflect the influence of deep dyspareunia on the sexual dysfunction of the analyzed population.

Conclusion Most patients exhibited sexual dysfunction, and deep dyspareunia was the pelvic painful symptom that showed correlation with sexual dysfunction.

Objetivo Avaliar a qualidade da função sexual em pacientes com suspeita de endometriose profunda infiltrativa.

Métodos Foi realizado um estudo observacional transversal prospectivo entre maio de 2015 e agosto de 2016, no qual foram analisados os dados clínicos e received

September 16, 2017

accepted

January 24, 2018
DOI https://doi.org/

10.1055/s-0038-1639593.

ISSN $0100-7203$.
Copyright $\odot 2018$ by Thieme Revinter

Publicações Ltda, Rio de Janeiro, Brazil
License terms

(c) (i) $\ominus$ (\$) 


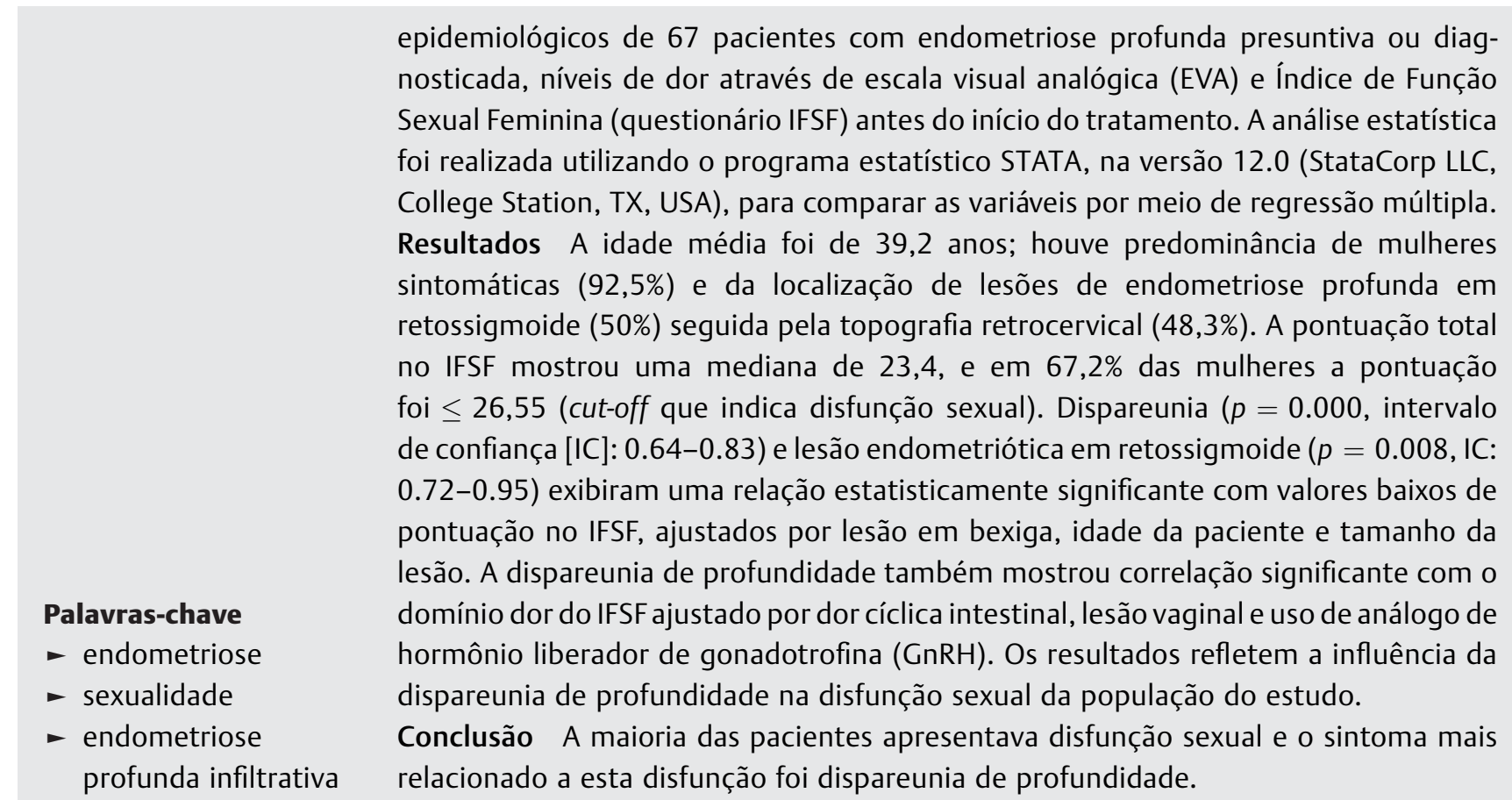

\section{Introduction}

Endometriosis is characterized by the presence of endometrium-like functional tissue located outside the uterine cavity, most often on the pelvic peritoneum and ovaries. It might present as deep and infiltrating lesions in the organs adjacent to the uterus-the bladder in the anterior pelvic compartment, retrocervical region, rectovaginal septum, vaginal fornices, rectosigmoid colon and cecal appendix in the posterior compartment. ${ }^{1,2}$ While the etiopathogenesis of the disease is not well known, some evidences suggest that a combination of retrograde menstrual flow with genetic, hormonal and immune factors and the cell response of the eutopic endometrium might contribute to the formation and development of endometriosis lesions. ${ }^{3}$

According to the available studies, the prevalence of this disease is $10-20 \%$ among women of reproductive age, ${ }^{4}$ but it might vary to be as high as $50 \%$ in populations of patients with specific clinical characteristics, such as infertility and chronic pelvic pain. ${ }^{5}$

With the help of laparoscopy, endometriosis might be classified according to its anatomical localization and extension. Among the available classification systems is the one formulated by the American Society of Reproductive Medicine, which is based on the appearance, size and depth of peritoneal and ovarian implants, presence, extension and type of adhesions, and degree of cul-de-sac obliteration. ${ }^{6}$ More recently, the ENZIAN classification was developed for deeply infiltrating lesions, in which the stages of disease are defined according to their localization and size. ${ }^{7,8}$ The bowel is frequently affected in the deep form of the disease, defined as endometriosis infiltrating deeper than $5 \mathrm{~mm}$ under the peritoneum. $^{7}$
Deep infiltrating lesions can be identified by physical examination, ${ }^{1}$ but transvaginal ultrasound ${ }^{9}$ and magnetic resonance imaging ${ }^{10}$ have been used for definition of the extension of the lesions with adequate accuracy.

There is no confirmed correlation between extension of the disease and severity of symptoms, reproductive prognosis or recurrence of pain in the long run. ${ }^{11}$

The clinical presentation of the disease is quite variable. Up to $25 \%$ of the patients might be asymptomatic, ${ }^{12} 30-50 \%$ might report infertility, ${ }^{12,13}$ and up to $80 \%$ complain of chronic pelvic pain (severe dysmenorrhea, deep dyspareunia and painful ovulation). ${ }^{14}$ In addition, perimenstrual urinary or rectal symptoms and chronic fatigue are common clinical complaints. ${ }^{12,15}$

The quality of life of patients with endometriosis is significantly impaired, while deep dyspareunia considerably affects their sexual life. ${ }^{16}$ In addition, dyspareunia is associated with anxiety, ${ }^{17,18}$ reduced frequency of sexual intercourse, reduction of sexual desire and arousal, and less orgasmic experiences. ${ }^{19,20}$ While these are subjective phenomena, assessment of the sexual function through validated questionnaires affords a better understanding of the impact of endometriosis on the quality of female sexuality. One of the best-established questionnaires for this purpose is the Female Function Sexual Index (FSFI), which has been validated for the Brazilian Portuguese language. ${ }^{21-23}$

Laparoscopic excision of endometriotic nodules, pharmacological treatment and the combination of both proved to be efficacious to reduce deep dyspareunia. ${ }^{24-28}$

Considering the intimate relationship between endometriosis and sexual dysfunction, ${ }^{17-20}$ we sought to assess the quality of the sexual function of women with suspected deep infiltrating endometriosis (DIE). 


\section{Methods}

The present prospective, observational and cross-sectional study was approved by the Brazilian national ethics committee.

On their first appointment at the endometriosis and chronic pelvic pain outpatient clinic of Hospital do Servidor Público Estadual Francisco Morato de Oliveira (HSPE-FMO), 67 consecutive patients with clinical suspicion of DIE were invited to participate in this study from May of 2015 to August of 2016.

We included sexually active women of reproductive age with suspected DIE at gynecological examination, ultrasonography (US) or magnetic resonance (MR) images and who agreed to participate in the study by signing an informed consent form. The participants were assured as to the confidentiality of the data and were informed they could withdraw their consent at any time.

All women were treated by means of continuous contraceptive or gonadotropin-releasing hormone $(\mathrm{GnRH})$ ana$\log$ to induce amenorrhea, and the surgical procedure was determined by non-responsive pain symptoms ${ }^{1}$ or intestinal and urinary risk of complications. The surgical procedures were performed laparoscopically with the aim of complete resection of DIE's lesions and histological exam was conducted in all specimen. The exclusion criteria consisted of incomplete filling out of the sexual function questionnaire and the withdraw of the informed consent.

We first collected data on the patients' age, number of pregnancies, surgical history of endometriosis, previous treatment, fertility condition, urinary and intestinal complains and pain symptoms: dysmenorrhea, dyspareunia and non-cyclic pelvic pain, which were quantified by means of the visual analog scale (VAS). Also, the characteristics of the endometriotic lesions on imaging tests (size, location and degree of infiltration) were described and classified preoperatively according to the ENZIAN classification, as it affords a satisfactory morphological description per affected compartment and lesion size. ${ }^{8}$

At first, before any surgical treatment, the participants filled out the FSFI questionnaire; some of them had already received clinical treatment previously but that information was taken into account as a possible confounding factor toward statistical analysis. The FSFI is a short, specific and multidimensional scale, previously adapted to the Portuguese language, with significant reliability and validity, ${ }^{21}$ which transforms subjective assessments into objective, quantifiable and analyzable data. ${ }^{23}$ The FSFI includes 19 questions corresponding to 6 domains- desire, arousal, lubrication, orgasm, satisfaction and pain or discomfort; the questions are scored from 0 to 5 . We calculated the overall score by adding the scores of the individual items in each domain, then we multiplied the sum by the domain factor-provided by the scale authors - and finally added the six domain scores. The overall score might vary from 2 to 36 , being that the higher the score the better the sexual function. ${ }^{21,22}$ Scores equal to or lower than 26.55 indicate sexual dysfunction. ${ }^{29}$
The collected data were entered in a Microsoft Excel for Windows spreadsheet (Microsoft Corp., Redmond, WA, USA). The statistical software STATA version 12.0 (StataCorp LLC, College Station, TX, USA) was used to perform descriptive and comparative analysis by means of Poisson's or logistic regression to investigate the correlation of the epidemiological and clinical data with the scores on the FSFI.

The categorical variables were expressed as percentages and the numerical ones as mean and standard deviation, when parametric distribution was observed, or as median and quartiles when their distribution was nonparametric.

For the logistic and Poisson regression models, we employed the forward stepwise method to select the variables potentially correlated with the outcomes. After univariate correlation analysis, the variables with $\mathrm{p} \leq 0.20$ or others with clinical relevance were selected to perform the multiple regressions. To improve the model fit, the significance level for the final correlations and adjusted multiple analysis was set at $p \leq 0.05$ with $95 \%$ confidence interval (CI). We subjected the final models to reliability tests to establish their goodness-of-fit, to wit, the Hosmer-Lemeshow test was used for the logistic regression model and the Pearson goodnessof-fit test for the Poisson regression model.

\section{Results}

From the 67 patients selected to participate in the study, none matched the exclusion criteria. Data corresponding to 67 women with age varying from 20 to 52 years old (mean: $39.19 \pm 6.67)$ were analyzed. Relative to the obstetrical history of the participants, $47.8 \%$ (32) had never been pregnant and $52.2 \%$ (35) had one to three children. The most prevalent delivery route was cesarean section, corresponding to $65.6 \%$ (21) of the cases, information that was found in patients' the medical records. About 19.4\% (13) of the sample had history of miscarriage, and $52.2 \%$ (35) had history of infertility. Finally, 26.2\% (17) of the participants had history of pelvic gynecological surgery.

About $92.5 \%$ (62) of the participants were symptomatic, the median duration of symptoms being 84 months (24120), that is, 7 years, varying from 1 to 420 months ( 35 years). The most prevalent symptoms included dysmenorrhea (94\%), dyspareunia (71.2\%) and non-cyclic pain (67.2\%). The distribution of painful symptoms according to the VAS scores is described on -Table $\mathbf{1}$.

Table 1 Distribution of painful symptoms on the VAS of women with deep infiltrating endometriosis

\begin{tabular}{|l|l|l|l|}
\hline VAS & $\begin{array}{l}\text { Dysmenorrhea } \\
n(\%)\end{array}$ & $\begin{array}{l}\text { Dyspareunia } \\
n(\%)\end{array}$ & $\begin{array}{l}\text { Non-cyclic } \\
\text { pain } \\
n(\%)\end{array}$ \\
\hline $0-4$ (mild) & $4(6)$ & $24(36.9)$ & $32(47.8)$ \\
\hline $5-6$ (moderate) & $9(13.5)$ & $14(21.5)$ & $14(20.9)$ \\
\hline $7-10$ (severe) & $54(80.5)$ & $29(41.6)$ & $21(31.3)$ \\
\hline
\end{tabular}

Abbreviations: $n$, number of subjects; $p$, p-value; VAS, visual analog scale. 
Specific bowel and urinary symptoms were reported by the patients, and the most common clinical presentation of these specific symptoms is the non-cyclic variety: constipation (28.4\%), non-cyclic dyschezia (20.9\%), cyclic dyschezia (16.4\%), non-cyclic abdominal bowel pain (16.4\%), cyclic abdominal bowel pain (9\%), non-cyclic hematochezia (7.5\%), cyclic hematochezia (6\%), non-cyclic urinary pain (3\%), cyclic urinary pain (1.5\%). About $28.4 \%$ of the sample reported constipation, with an average interval of 2.28 days between stools.

Some patients (34.3\%) were referred to the outpatient clinic already receiving treatment, which included combined oral contraceptives (COC) (17.9\%), progestin alone (11.9\%), and GnRH analog (4.5\%).

Sixty medical records had information on the localization of deep infiltrating endometriosis lesions by means of specialized imaging tests, such as magnetic resonance imaging of the pelvis and transvaginal ultrasound with bowel preparation. About $45 \%$ (27) of the sample exhibited lesions suspected of cystic ovarian endometriosis concomitant with bowel lesions, which were bilateral in $16.6 \%$ (9) of the cases. As to the distribution of lesions, 50\% (30) were located on the rectosigmoid colon, $48.3 \%$ (29) in the retrocervical region, $11.7 \%$ (7) in the vaginal fornices, $8.3 \%(5)$ in the vaginal septum and $5.9 \%$ (3) on the bladder reflection.

The mean size of the lesions was $2.3 \mathrm{~cm}(1.6-3.0 \mathrm{~cm})$, varying from 0.7 to $11.4 \mathrm{~cm}$. Forty-nine cases could be classified according to the ENZIAN system (-Table 2). Lesions on the vaginal fornices, vagina or rectovaginal septum were classified as ENZIAN stage A, retrocervical lesions as stage $B$ and bowel lesions as stage $C$.

About $80 \%$ (24) of the lesions reached the muscle layer of the affected bowel loop wall, while $20 \%$ extended into the submucosal layer. Most lesions ( $73.3 \%$ ) affected up to $25 \%$ of the bowel loop circumference.

The median overall score on the FSFI was 23.4 (18-28.6); the proportion of cases with score $\leq 26.55$ was $67.2 \%$ (45). The domain scores were: desire 3 (2.4-3.6), arousal 3.9 (2.7$4.5)$, lubrication 4.8 (3.3-5.7), orgasm $4.4(2.8-5.6)$, satisfaction 4.8 (33.2-5.2) and pain 3.6 (2-5.2).

We analyzed the correlation between predictor variables by means of multiple regression analysis to identify possible confounding factors and selected the ones with higher statistical significance or better fit to the model, thus reducing the odds of colinearity or confusion in the final model.

Multiple logistic regression evidenced significant correlation between dyspareunia and sexual dysfunction (FSFI score $\leq 26.55$ ) adjusted by lesion size and patients' age, as shown in - Table 3.

Table 2 Distribution of deep infiltrating endometriosis lesions according to the ENZIAN classification

\begin{tabular}{|l|l|l|l|l|}
\hline \multirow{2}{*}{$\begin{array}{l}\text { Lesion } \\
\text { size }(\mathrm{cm})\end{array}$} & \multirow{2}{*}{ Grade } & \multicolumn{3}{|l|}{ Compartment } \\
\cline { 3 - 5 } & & $\mathrm{A}$ & $\mathrm{B}$ & $\mathrm{C}$ \\
\hline$<1$ & 1 & 1 & 2 & 1 \\
\hline $1-3$ & 2 & 3 & 14 & 18 \\
\hline$>3$ & 3 & 1 & 4 & 5 \\
\hline
\end{tabular}

Table 3 Multiple logistic regression of predictor variables and sexual dysfunction corresponding to patients with deep infiltrating endometriosis

\begin{tabular}{|l|l|l|}
\hline Variables & $\begin{array}{l}\text { Unadjusted } \\
\text { analysis } \\
\boldsymbol{p}(\mathrm{CI})\end{array}$ & $\begin{array}{l}\text { Final adjusted } \\
\text { model } \\
\boldsymbol{p}(\mathrm{CI})\end{array}$ \\
\hline Dyspareunia & $0.002(0.68-3.01)$ & $0.003(2.75-140.54)$ \\
\hline Lesion size & $0.112(-0.01-0.11)$ & $0.052(0.991 .22)$ \\
\hline Age & $0.225(-0.02-0.12)$ & $0.069(0.99-1.23)$ \\
\hline
\end{tabular}

Abbreviations: $\mathrm{Cl}$, confidence interval; $p$, $\mathrm{p}$-value.

Hosmer-Lemeshow $=0.6255$.

The Poisson multiple regression detected significant inverse correlation of variables dyspareunia and rectosigmoid localization with higher overall score on the FSFI, adjusted by age, lesion size and presence of lesions in the bladder, as described in - Table 4.

The Poisson multiple regression was also used to analyze the correlation between the study variables and sexual function domains- desire, arousal, lubrication, orgasm, satisfaction and pain or discomfort. No statistically significant correlation was found between the selected predictor variables and desire, arousal, lubrication, orgasm or satisfaction. In turn, variable deep dyspareunia exhibited inverse correlation with higher score on the FSFI domain pain, adjusted by cyclic bowel pain, endometriosis lesion on the vaginal fornix and use of GnRH analog (- Table 5 ).

\section{Discussion}

The average age of the patients in the present study corresponds to the age range in which endometriosis is usually diagnosed, that is, the fourth decade of life. ${ }^{30,31}$ Relative to the obstetrical history, the prevalence of women with no previous pregnancy and primary or secondary infertility was

Table 4 Poisson multiple regression analysis of predictor variables and overall score on FSFI corresponding to patients with deep infiltrating endometriosis

\begin{tabular}{|l|l|l|}
\hline Variables & $\begin{array}{l}\text { Unadjusted } \\
\text { analysis } \\
p(\mathrm{Cl})\end{array}$ & $\begin{array}{l}\text { Adjusted } \\
\text { analysis } \\
\boldsymbol{p}(\mathrm{Cl})\end{array}$ \\
\hline Dyspareunia & $0.000(-0.34-0.13)$ & $0.000(0.64-0.83)$ \\
\hline $\begin{array}{l}\text { Rectosigmoid } \\
\text { lesion }\end{array}$ & $0.041(-0.21-0.00)$ & $0.008(0.72-0.95)$ \\
\hline $\begin{array}{l}\text { Bladder } \\
\text { reflection } \\
\text { lesion }\end{array}$ & $0.052(-0.35-0.00)$ & $0.151(0.43-0.13)$ \\
\hline Lesion size & $0.059(-0.007-0.00)$ & $0.470(0.99-1.00)$ \\
\hline Age & $0.067(-0.01-0.00)$ & $0.174(0.98-1.00)$ \\
\hline
\end{tabular}

Abbreviations: $\mathrm{Cl}$, confidence interval; $\mathrm{FSFI}$, female sexual function index; $p$, p-value.

Pearson goodness-of-fit $=0.2304$. 
Table 5 Poisson multiple regression of predictor variables and domain pain in patients with deep infiltrating endometriosis

\begin{tabular}{|l|l|l|}
\hline Variables & $\begin{array}{l}\text { Unadjusted } \\
\text { analysis } \\
p(\mathrm{CI})\end{array}$ & $\begin{array}{l}\text { Adjusted } \\
\text { analysis } \\
p(\mathrm{CI})\end{array}$ \\
\hline Dyspareunia & $0.000(0.45-0.75)$ & $0.003(0.49-0.86)$ \\
\hline Cyclic bowel pain & $0.065(0.97-2.12)$ & $0.256(0.84-1.87)$ \\
\hline $\begin{array}{l}\text { Lesion on vaginal } \\
\text { fornix }\end{array}$ & $0.152(0.43-1.13)$ & $0.236(0.46-1.21)$ \\
\hline $\begin{array}{l}\text { Use of GnRH } \\
\text { analogue }\end{array}$ & $0.159(0.24-1.25)$ & $0.291(0.06-2.29)$ \\
\hline
\end{tabular}

Abbreviations: $\mathrm{Cl}$, confidence interval; $\mathrm{GnRH}$, gonadotropin-releasing hormone; $p$, p-value.

Pearson goodness-of-fit $=0.99$.

high, which might be explained by the effect of immune cells and the hostile environment caused by the disease. ${ }^{32}$

As the sample was composed of women cared for at an outpatient clinic for treatment of chronic pelvic pain, the high prevalence of symptomatic patients (92.5\%) is easy to understand.

In the present study, the prevalence of dysmenorrhea and dyspareunia was $94 \%$ and $71.2 \%$, respectively. These rates are much higher than the ones reported by Bellelis et al (2010); ${ }^{29}$ however, these authors only considered severe painful symptoms. Despite the low prevalence, specific bowel and urinary symptoms were also reported by the patients.

As the present study also shows, bowel complaints are common manifestations among patients with DIE and might interfere with the bowel function; ${ }^{2}$ and overall quality of life and sexual function. We were not able to establish a direct relationship between lesion size or location and FSFI scores indicative of sexual dysfunction, which agrees with reports by other authors. ${ }^{11}$

As concerns the negative impact of symptoms on the female sexual function, the prevalence of sexual dysfunction among the patients with suspected or confirmed diagnosis of DIE was $67.2 \%$. In the studies by Di Donato et al $(2014)^{16}$ and Jia et al (2013), ${ }^{33}$ this rate was $58 \%$ and $73 \%$, respectively.

We found a direct correlation between dyspareunia and sexual dysfunction, defined as an FSFI score below 26.55. ${ }^{29}$

In addition, we detected an inverse correlation between dyspareunia and bowel lesion with a higher FSFI score. The correlation is inverse in this case because higher FSFI scores indicate better sexual function, therefore, lesion size and dyspareunia correlated with lower scores, which is indicative of sexual dysfunction. Relative to the individual FSFI domains, our models detected a correlation between dyspareunia and the pain domain.

It is a fact well established in the literature that the experience of pain is reinforced in subsequent intercourse experiences, which creates a cognitive pattern characterized by negative expectations, which in turn affects the sexual function and causes suffering, anguish or interpersonal difficulties, making the women unable to participate in intercourse as they would wish. ${ }^{18,20,34,35}$
Rectosigmoid lesions are the most prevalent form of presentation of DIE and usually cause painful symptoms, and its prevalence might account for the inverse correlation found between FSFI scores and lesions in that location.

We did not find a statistically significant correlation between the analyzed predictor variables and the FSFI domains desire, arousal, lubrication, orgasm or satisfaction. Only the variable deep dyspareunia exhibited an inverse correlation with higher scores on the pain domain. Other authors observe that patients with endometriosis develop strategies to cope with pain due, for instance, to a desire to become pregnant, which may have increased the individual scores on the other FSFI domains. ${ }^{36}$

The lack of information on the partners' or relationship status is a limitation of the FSFI. Further limitations of the present study derive from the lack of assessment of other factors, such as comorbidities, family and religious aspects, and the women's personal values, which determine their sexual choices and behaviors.

In addition, the lack of randomization, the study design and the small sample size might limit the interpretation and external validity of the results of the present study. However, we have already developed a research line to continue the longitudinal investigation so as to compare the sexual function outcomes before and after treatment for DIE, as the results might afford a better understanding of the effects of therapeutic interventions on the quality of the female sexual experience.

\section{Conclusion}

The results of the present study show that dyspareunia exerts a negative influence on the overall FSFI score and also on the pain domain. These findings reinforce the fact that female sexual dysfunction is a public health problem in women with suspected DIE, thus demanding special attention from gynecologists.

Conflicts to interest

The authors declare that there are no conflicts of interest.

\section{References}

1 Abrão MS, Petraglia F, Falcone T, Keckstein J, Osuga Y, Chapron C. Deep endometriosis infiltrating the recto-sigmoid: critical factors to consider before management. Hum Reprod Update 2015;21 (03):329-339. Doi: 10.1093/humupd/dmv003

2 Wolthuis AM, Meuleman C, Tomassetti C, D'Hooghe T, de Buck van Overstraeten A, D'Hoore A. Bowel endometriosis: colorectal surgeon's perspective in a multidisciplinary surgical team. World J Gastroenterol 2014;20(42):15616-15623. Doi: 10.3748/wjg. v20.i42.15616

3 Kennedy S, Bergqvist A, Chapron C, et al; ESHRE Special Interest Group for Endometriosis and Endometrium Guideline Development Group. ESHRE guideline for the diagnosis and treatment of endometriosis. Hum Reprod 2005;20(10):2698-2704. Doi: 10.1093/humrep/dei135

4 Bricou A, Batt RE, Chapron C. Peritoneal fluid flow influences anatomical distribution of endometriotic lesions: why Sampson seems to be right. Eur J Obstet Gynecol Reprod Biol 2008;138(02): 127-134. Doi: 10.1016/j.ejogrb.2008.01.014 
5 Alkatout I, Egberts JH, Mettler L, et al. [Interdisciplinary Diagnosis and Treatment of Deep Infiltrating Endometriosis]. Zentralbl Chir 2016;141(06):630-638. Doi: 10.1055/s-0034-1383272

6 Nácul AP, Spritzer PM. [Current aspects on diagnosis and treatment of endometriosis]. Rev Bras Ginecol Obstet 2010;32(06): 298-307. Doi: 10.1590/S0100-72032010000600008

7 Haas D, Chvatal R, Habelsberger A, Wurm P, Schimetta W, Oppelt P. Comparison of revised American Fertility Society and ENZIAN staging: a critical evaluation of classifications of endometriosis on the basis of our patient population. Fertil Steril 2011;95(05): 1574-1578. Doi: 10.1016/j.fertnstert.2011.01.135

8 Haas D, Wurm P, Shamiyeh A, Shebl O, Chvatal R, Oppelt P. Efficacy of the revised Enzian classification: a retrospective analysis. Does the revised Enzian classification solve the problem of duplicate classification in rASRM and Enzian? Arch Gynecol Obstet 2013; 287(05):941-945. Doi: 10.1007/s00404-012-2647-1

9 Guerriero S, Ajossa S, Orozco R, et al. Accuracy of transvaginal ultrasound for diagnosis of deep endometriosis in the rectosigmoid: systematic review and meta-analysis. Ultrasound Obstet Gynecol 2016;47(03):281-289. Doi: 10.1002/uog.15662

10 Medeiros LR, Rosa MI, Silva BR, et al. Accuracy of magnetic resonance in deeply infiltrating endometriosis: a systematic review and meta-analysis. Arch Gynecol Obstet 2015;291(03): 611-621. Doi: 10.1007/s00404-014-3470-7

11 Vercellini P, Fedele L, Aimi G, Pietropaolo G, Consonni D, Crosignani PG. Association between endometriosis stage, lesion type, patient characteristics and severity of pelvic pain symptoms: a multivariate analysis of over 1000 patients. Hum Reprod 2007;22 (01):266-271. Doi: 10.1093/humrep/del339

12 Bulletti C, Coccia ME, Battistoni S, Borini A. Endometriosis and infertility. J Assist Reprod Genet 2010;27(08):441-447. Doi: 10.1007/s10815-010-9436-1

13 Jacobson TZ, Barlow DH, Koninckx PR, Olive D, Farquhar C. Laparoscopic surgery for subfertility associated with endometriosis. Cochrane Database Syst Rev 2002;(04):CD001398. Doi: 10.1002/14651858.CD001398

14 Vercellini P, Somigliana E, Buggio L, Barbara G, Frattaruolo MP, Fedele L. "I can't get no satisfaction": deep dyspareunia and sexual functioning in women with rectovaginal endometriosis. Fertil Steril 2012;98(06):1503-11.e1. Doi: 10.1016/j.fertnstert.2012.07.1129

15 Morsch DM, Carneiro MM, Lecke SB, et al. c-fos gene and protein expression in pelvic endometriosis: a local marker of estrogen action. J Mol Histol 2009;40(01):53-58. Doi: 10.1007/s10735-009-9212-7

16 Di Donato N, Montanari G, Benfenati A, et al. Do women with endometriosis have to worry about sex? Eur J Obstet Gynecol Reprod Biol 2014;179:69-74. Doi: 10.1016/j.ejogrb.2014.05.022

17 Jones G, Jenkinson C, Kennedy S. The impact of endometriosis upon quality of life: a qualitative analysis. J Psychosom Obstet Gynaecol 2004;25(02):123-133. Doi: 10.1080/01674820400002279

18 Pluchino N, Wenger JM, Petignat P, et al. Sexual function in endometriosis patients and their partners: effect of the disease and consequences of treatment. Hum Reprod Update 2016;22 (06):762-774. Doi: 10.1093/humupd/dmw031

19 Laumann EO, Paik A, Rosen RC. Sexual dysfunction in the United States: prevalence and predictors. JAMA 1999;281(06): 537-544. Doi: 10.1001/jama.281.6.537

20 Elmerstig E, Wijma B, Berterö C. Why do young women continue to have sexual intercourse despite pain? J Adolesc Health 2008;43 (04):357-363. Doi: 10.1016/j.jadohealth.2008.02.011

21 Leite APL, Moura EA, Salles AAS, Mattar R, Souza E, Camano L. Validation of the Female Sexual Function Index in Brazilian pregnant women. Rev Bras Ginecol Obstet 2007;29:396-401. Doi: 10.1590/ S0100-72032007000800003

22 Hentschel H, Alberton DL, Capp E, Goldim JR, Passos EP. Validação do Female Sexual Function Index (FSFI) para uso em português. Rev HCPA 2007;27:10-14

23 Rosen R, Brown C, Heiman J, et al. The Female Sexual Function Index (FSFI): a multidimensional self-report instrument for the assessment of female sexual function. J Sex Marital Ther 2000;26 (02):191-208. Doi: 10.1080/009262300278597

24 Thomassin I, Bazot M, Detchev R, Barranger E, Cortez A, Darai E. Symptoms before and after surgical removal of colorectal endometriosis that are assessed by magnetic resonance imaging and rectal endoscopic sonography. Am J Obstet Gynecol 2004;190 (05):1264-1271. Doi: 10.1016/j.ajog.2003.12.004

25 Van den Broeck U, Meuleman C, Tomassetti C, et al. Effect of laparoscopic surgery for moderate and severe endometriosis on depression, relationship satisfaction and sexual functioning: comparison of patients with and without bowel resection. Hum Reprod 2013;28(09):2389-2397. Doi: 10.1093/humrep/det260

26 Crosignani PG, Luciano A, Ray A, Bergqvist A. Subcutaneous depot medroxyprogesterone acetate versus leuprolide acetate in the treatment of endometriosis-associated pain. Hum Reprod 2006; 21(01):248-256. Doi: 10.1093/humrep/dei290

27 Vercellini P, Pietropaolo G, De Giorgi O, Pasin R, Chiodini A, Crosignani PG. Treatment of symptomatic rectovaginal endometriosis with an estrogen-progestogen combination versus lowdose norethindrone acetate. Fertil Steril 2005;84(05):1375-1387. Doi: $10.1016 /$ j.fertnstert.2005.03.083

28 Schlaff WD, Carson SA, Luciano A, Ross D, Bergqvist A. Subcutaneous injection of depot medroxyprogesterone acetate compared with leuprolide acetate in the treatment of endometriosis-associated pain. Fertil Steril 2006;85(02):314-325. Doi: 10.1016/j. fertnstert.2005.07.1315

29 Wiegel M, Meston C, Rosen R. The female sexual function index (FSFI): cross-validation and development of clinical cutoff scores. J Sex Marital Ther 2005;31(01):1-20. Doi: 10.1080/00926230590475206

30 Bellelis P, Dias JA Jr, Podgaec S, Gonzales M, Baracat EC, Abrão MS. Epidemiological and clinical aspects of pelvic endometriosis-a case series. Rev Assoc Med Bras 2010;56:467-471. Doi: 10.1590/ S0104-42302010000400022

31 Arruda MS, Petta CA, Abrão MS, Benetti-Pinto CL. Time elapsed from onset of symptoms to diagnosis of endometriosis in a cohort study of Brazilian women. Hum Reprod 2003;18(04):756-759. Doi: 10.1093/humrep/deg136

32 Giudice LC, Kao LC. Endometriosis. Lancet 2004;364(9447):1789-1799. Doi: 10.1016/S0140-6736(04)17403-5

33 Jia SZ, Leng JH, Sun PR, Lang JH. Prevalence and associated factors of female sexual dysfunction in women with endometriosis. Obstet Gynecol 2013;121(03):601-606. Doi: 10.1097/ AOG.0b013e3182835777

34 Lara LA, Rosa e Silva AC, Romão AP, Junqueira FR. [The assessment and management of female sexual dysfunction]. Rev Bras Ginecol Obstet 2008;30(06):312-321. Doi: 10.1590/S010072032008000600008

35 Mendonça CR, Silva TM, Arrudai JT, García-Zapata MTA, Amaral WN. Função sexual feminina: aspectos normais e patológicos, prevalência no Brasil, diagnóstico e tratamento. Femina 2012; 40:195-202

36 Evangelista A, Dantas T, Zendron C, Soares T, Vaz G, Oliveira MA. Sexual function in patients with deep infiltrating endometriosis. J Sex Med 2014;11(01):140-145. Doi: 10.1111/jsm.12349 